\title{
ARE WE A LEARNING ORGANISATION? AN ASSESSMENT MODEL FOR CONTINUOUS IMPROVEMENT
}

\author{
C.C. van Waveren, A. Bouwer and I.F. Esterhuizen \\ Department of Engineering and Technology Management \\ University of Pretoria \\ cvwaver@eng.up.ac.za
}

\begin{abstract}
It is generally agreed that one way for organisations to be competitive in the new global economy is by embracing the principles of Peter Senge's "The Fifth Discipline" and becoming "learning organisations". The literature on the nature of learning organisations is extensive, but few of the discussions break through the philosophical barrier and actually address practical ways in which organisations can move away from traditional organisation thinking models and become learning organisations. This paper discusses a 9-S framework and an accompanying measurement model that can be used by organisations to determine whether they are learning organisations, and if not, where and how they need to improve. The framework is based on the Htt 8-S framework, and the measurement model takes the form of a series of weighted questions and results that graphically represent how successful an organisation has been in its quest to become a learning organisation. A practical implementation of the measurement model that focuses on the planning aspect of organisational management is included in the paper.
\end{abstract}

\section{OPSOMMING}

Vir 'n organisasie om kompeterend in 'n wereldekonomie te wees, word daar algemeen aanvaar dat die organisasie sekere leergerigtheidseienskappe moet bemeester soos beskryf in Peter Senge se boek "The Fifth Discipline". Omvattende literatuur oor die leergerigtheidseienskappe van organisasies bestaan, maar daar is egter min inligting oor praktiese maniere om 'n tradisionele organisasie na 'n leergerigtheidsorganisasie oor te skakel. Hierdie artikel bespreek 'n 9-S raamwerk asook 'n gepaardgaande evalueringsmodel wat gebruik kan word om 'n organisasie te meet aan sekere leergerigtheidseienskappe. Die raamwerk is gebaseer op die Hitt 8 -S raamwerk en die evalueringsmodel maak gebruik van geweegde vrae waarvan die resultate grafies vertoon word om die sukses van leergerigtheid in die organisasie voor te stel. 'n Gevallestudie wat die beplanningsleergerigtheid van 'n spesifieke organisasie evalueer, is ook ingesluit. 


\section{INTRODUCTION}

Ever since Senge published "The Fifth Discipline" in 1990, the concept of a "learning organisation" has been extensively discussed and analysed in the literature. However, there seems to be a lack of consensus on what the practical definition of a learning organisation is.

In order to address this lack of consensus, concepts such as the McKinsey 7-S framework and Hitt's 8-S framework were used, and developed upon, to build a model against which companies could be measured objectively.

This paper focuses on the assessment of organisational activities against the learning characteristics necessary for continuous self-renewal within organisations. The assessment model is based on a series of weighted questions designed to measure compliance with the principles and concepts of a learning organisation. The results of the assessment are graphically represented and clearly illustrate how well an organisation's activities comply with the necessary learning characteristics. A specific case study that measures the planning activities of an organisation is included.

The model can be used and adapted for a variety of organisational activities as an internal measure of improvement on a time history basis. The outcome of the assessment indicates areas of strengths and weaknesses in the organisation.

\section{THE LEARNING ORGANISATION}

Senge [16],[17] defines a learning organisation as an organisation where people continually expand their capacity to create the results they truly desire, where new and expansive patterns of thinking are nurtured, where collective aspiration is set free and where people are continually learning how to learn together. A learning organisation can also be seen as an organisation that is skilled at creating, acquiring and transferring knowledge, and at modifying its behaviour to reflect new knowledge and insight [7],[8],[19].

\subsection{Organisational Learning Disciplines}

Learning organisations are based on several ideas and principles that are integral to the very structure of the organisation, both internally as well as externally. Internally in terms of how individuals within the organisation are encouraged to interact with each other and externally in terms of how inter organisational practices are carried out. Senge [3],[16] defines five core disciplines on which a learning organisation should be built. These disciplines are:

\subsubsection{Systems Thinking}

At the heart of systems thinking is an awareness of the interconnectedness (and varying levels of interdependency) of persons in teams, of teams in organisations, and organisations in the larger environment. To take a systems perspective means to function individually and as part of a team to optimise the organisation as a whole. 


\subsubsection{Personal Mastery}

Personal mastery entails charting a course of development that leads to a special level of proficiency through life-long learning. This learning is not only in the areas related to the product or service of the organisation but includes such areas as enhancing interpersonal competence, personal awareness, emotional maturity, and an enlarging understanding of the ethical and moral dimensions of organisational life.

\subsubsection{Mental Models}

Our responses to new situations are influenced by our ingrained assumptions and generalisations about how things work in organisations. These mental models enable us to rapidly size up new situations and take action and can be found at the individual, team, and organisational level. In the learning organisation mental models are freely shared, rigorously scrutinised, and revised as necessary at the personal, team, and organisational levels.

\subsubsection{Building Shared Vision}

Goals, values, and missions will have the most impact on behaviour in an organisation if they are widely shared and owned by persons throughout the organisation. This larger shared picture of the future emerges from the partial visions of individuals and teams. A shared vision produces a much higher level of sustained commitment than is possible when the vision is imposed from above.

\subsubsection{Team Learning}

Team learning has to do with improving the processes within a team to improve its effectiveness. When effective processes are in place the team can engage in its primary task of providing a product or service. Team learning requires a systems perspective so that persons see themselves as interdependent on other team members and their team as interdependent on other teams that make up the larger organisation.

\section{Building a Learning Organisation}

Although organisations might understand the principles and definitions of a learning organisation and environment, the practical implementation thereof might not be that obvious. Garvin [8] suggests that for effective implementations, the three aspects of meaning, management and measurement must be addressed.

In order to address these aspects, five activities are mentioned in which a learning organisation must be skilled. These are discussed in the following sections:

\subsubsection{Systematic Problem Solving}

Problem diagnoses and decisions must be based on well-founded scientific methods using factual information, mathematical and statistical tools. Accuracy and precision are essential for learning and employees must become more disciplined in their thinking as well as more 
attentive to details. Problems must be broken down to the root causes to avoid sloppy reasoning.

\subsubsection{Experimentation with New Approaches}

Experimentation is usually motivated by opportunity and expanding horizons and the activity involves the systematic searching for and testing of new knowledge [5],[18]. Two kinds of experimentation exist namely:

- Ongoing programs, which normally involves a continuing series of small experiments designed to produce incremental gains in knowledge.

- Demonstration projects, which are usually larger and involve holistic, system wide changes with the goal of developing new organisational capabilities.

To be successful in such experiments, training in the design thereof or the improvement in creativity techniques is essential. Because experimentation is associated with risk, incentive schemes or systems must be put in place to favour this risk taking.

\subsubsection{Learning from their Own Experience and Past History}

Organisations must review their successes and failures, assess them systematically and record the lessons in a form that employees find open and accessible.

\subsubsection{Learning from the Experiences and Best Practices of Others}

Sometimes the most powerful insights come from looking outside one's immediate environment to gain new perspectives and to benchmark your activities with those of others. Benchmarking is therefore an ongoing investigation and a learning experience that ensures that the best industry practices are uncovered, analysed, adopted and implemented.

It is important to remember that learning will only occur in a receptive environment. Managers can't be defensive and must be open to criticism or bad news.

\subsubsection{Transferring Knowledge Quickly and Efficiently Throughout the Organisation}

For learning to be more than a local affair, knowledge must be spread quickly and efficiently throughout the organisation. This can be done using electronic media and digital networks.

Personnel rotation is also a powerful method of transferring knowledge while line to staff transfers is another option. [1]

Education and training programs can also be used to transfer knowledge. It is however important that a high emphasis is placed on implementation during these training programs to gain the best learning benefit. 


\section{EVALUATION MODEL}

\subsection{Introduction}

A theoretical model that measures the conformance of a company or activity to that of a learning organisation was developed from the appropriate literature.

The model that has been developed can be applied to any of the processes in an organisation. The outputs of the model evaluate an organisation's activities in two ways:

- It gives an indication of how well the organisation's processes conform to the requirements of a learning approach.

- It compares the actual learning characteristics of the different processes within the organisation.

The success of the model depends on the accuracy and completeness of the defined model characteristics as well as the scoring method used. The model characteristics, the evaluation matrix, the scoring methods, the graphical representation and the interpretation of the results are discussed in the following sections.

\subsection{Model Characteristics}

The theoretical evaluation model as developed by the authors builds on the McKinsey 7-S framework, as later expanded by Hitt [10] into an 8-S framework. Based on the 8-S framework a generic 9-S framework has been developed as depicted in Figure 1.

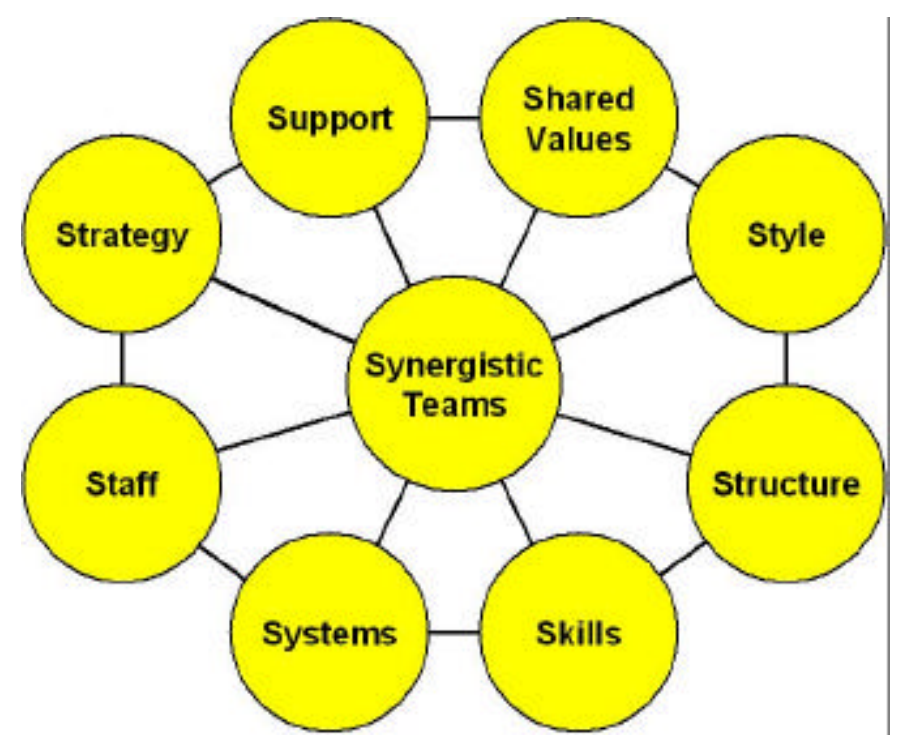

Figure 1. 9-S Planning whilst Learning Model Characteristics

The characteristics of the generic 9-S model are discussed in the following sections. 


\subsubsection{Shared Values}

One of the 5 'component technologies' mentioned by Senge [16] is 'building a shared vision'. Leaders need to be constantly aware of the vision of the future they intend to create. The leader needs to translate this personal vision into a shared vision. The vision is part of the beliefs and values guiding every organisation. These values communicate to all members "what we stand for" and "what is important to us". Whether the values are explicit or implicit, they constitute the essence of the organisation's culture. The traditional organisation has held to two primary values, namely

- Efficiency: doing things right, and

- Effectiveness: doing the right things.

These values are vital to the survival of any organisation, but they are not sufficient in the context of a learning organisation. According to Hitt [10], the learning organisation has two core values that allow it to flourish in an ever-changing environment, namely

- Excellence: always striving for the highest standards in everything one does commensurate with the needs of the customer and the resources available, and

- Self-renewal: creating a framework within which continuous innovation and rebirth can occur - a framework that allows the organisation to adapt to a continually changing environment while maintaining the integrity of its own identity.

As Hitt states, "the leitmotiv of a learning organisation is excellence through self-renewal".

\subsubsection{Style of Leadership}

Lao Tzu, in the Tao Te Ching, said 'Of the best leader, when the job is done the people say 'we did it ourselves."' This quote captures the essence of the role of the manager in a true learning organisation. In order to create a culture of learning in an organisation, the role of the manager must change to that of a facilitator and coach [14]. Here the manager's leadership role is accentuated. The manager must empower the staff to act. This can be done by delegating authority, thus giving the staff an opportunity to learn by doing and having an active participative role in the process. The manager must also view his own activities as a learning process. His management style must therefore set an example of that of an active learner to others in the organisation.

\subsubsection{Structure}

Efficient and effective information sharing is one of the lodestones of a learning organisation. Traditional organisations have activities that must be systematically arranged and carried out. These orderly activities have been achieved by establishing a clear-cut hierarchical structure of functions that channel and restrain the flow of information. The learning organisation has shown that, although orderliness is necessary, it is not sufficient. The organisation needs flexibility and spontaneity in its structure in order to prepare for and respond to an ever changing and challenging environment. The learning organisation incorporates stability and flexibility as complimentary dimensions that enhance the clarity and orderliness as well as the flexibility and spontaneity of the organisation. This is done by establishing dynamic networks 
within a vertical structure. Charan [4] highlights some of the principal features of dynamic networks:

- A network reshapes how and by whom essential business decisions are made.

- It integrates decisions horizontally at the lowest managerial levels and with superior speed.

- In effect, a network identifies the "small company inside the large company" and empowers it to make appropriate decisions.

- It enables the right people in the organisation to converge faster and in a more focused way than the competition in order to meet customer needs and build concrete advantage.

- The foundation of a network is its social architecture: what happens when the network comes together and how it will be managed.

The value added by dynamic networks is the expanded flow of information brought about by the permeability and flexibility of the organisational boundaries. The expanded flow of information allows all members of the organisation to make use of all the intelligence available within the organisation.

\subsubsection{Skills}

Senge [16] differentiates between two types of learning necessary in any organisation, namely adaptive learning and generative learning. Adaptive learning is essentially "survival learning" while generative learning enhances an organisation's ability to create. Argyris [2] refers to the two types of learning as single loop and double loop learning. Adaptive learning is more prevalent in traditional organisations whereas the learning organisation uses generative learning to enhance adaptive learning.

By continually going through the process of evaluate, plan, do, check and amend generative learning takes place. This generative learning is called a never-ending improvement helix [15].

Adaptive learning focuses on skills such as problem solving and job mastery while generative learning emphasis skills such as creative questioning and systems thinking.

\subsubsection{Systems}

Kaplan and Norton state that "what you measure is what you get". If only the short-term financial results are measured then more than likely only the short-term financial results will improve. It is therefore important that the measurement process in a learning organisation is not only focused on a single dimension. A broader perspective of what is happening in the organisation as a whole must be obtained. With a systems perspective it is possible to continually improve all aspects of the organisation and not only one aspect, as is usually the case with a focused measurement system.

A good example of a broader and more balanced measurement tool, is the balanced scorecard as introduced by Kaplan and Norton in different issues of Harvard Business Review articles [11],[12]. The concept of a balanced scorecard provides organisations with a means of 
obtaining a systems perspective through measurements. The four main characteristics of a balanced scorecard are:

- It is a top-down reflection of the organisation's mission and strategy

- It is forward-looking in that it addresses current and future success

- It integrates external and internal measurements

- It helps management to focus on critical success factors such as excellence, organisational renewal, financial performance and customer satisfaction.

\subsubsection{Staff}

In a learning organisation, the staff members must be committed to lifelong learning. This is true throughout all levels of the organisation, from senior management down to the workers at ground level. If all members of the organisation are committed to learning, a culture of learning will automatically develop. An environment needs to be created where learning is encouraged. There must be an atmosphere of trust between members of the organisation and mistakes must be tolerated as part of the learning process. Where mistakes occur or individuals lack the proper skills, training must be given. Individuals must be encouraged to admit their inadequacies and ask questions in order to improve their planning skills.

\subsubsection{Strategy}

In the learning organization individual mental models are shared between the members which result in a shared vision of the future. The shared mental model is adaptive to new knowledge. Emphasis is placed on the process of aligning the model with current reality, and not on the final product. It leaves room for the individual to operate within the framework of the mental model. This provides the freedom for original lateral thinking.

\subsubsection{Synergistic Teams}

In order for teams in a learning organisation to be effective, there must be an active and open dialog between the members. This open and active dialog facilitates the development of synergistic teams. Here the emphasis lies on increasing the total intelligence of the team instead of having a team whose total intelligence is no greater than the intelligence of the individual members. The team must learn as a whole, with inputs from each member. Where necessary, intelligence can be gathered from outside the team and incorporated in the team learning process. This could be achieved by the active use of cross-functional teams, where the input from individual members can give a different perspective to the over-all process. Encouraging inputs from members at lower levels with regards to the processes can facilitate and help the management team in formulating plans. Using the expertise and knowledge of different members of the team ensures that activities are done effectively and limits mistakes.

\subsubsection{Supporting Infrastructure and Technology}

As mentioned earlier, efficient and effective information sharing is of great importance in a learning organisation. Advances in information technology systems have been a boon for organisations wishing to streamline and optimise the flow of information to all stakeholders. Interactive knowledge base systems, EDI, intranets, the Internet, groupware systems and 
teleconferencing systems are some of the technologies that have in recent years made it possible to enhance information sharing. In addition to information technology, the increasing availability and power of desktop computing has made it feasible to make management information systems available to all levels of the organisation. [6]. Active learning infrastructures such as open plan offices, planning rooms, whiteboards and informal meeting areas contribute to knowledge transfer and emphasise learning as an integral part of all organisational activities [9].

\subsection{Evaluation Matrix \& Scoring}

All processes can be evaluated and scored by using evaluation criteria for each model characteristic. Scoring can be done in various ways e.g.:

- Simplistic, Yes/No scoring

- A weighted, Yes/No scoring method where the different evaluation criteria are weighted in terms of importance

- A range scoring method

- A weighted range scoring method

Scoring can be done on an individual basis or by group consensus.

An example of a completed evaluation matrix using a simplistic Yes/No scoring method is depicted in Table 1. An advantage of this evaluation matrix is that it is expandable to incorporate as many processes of the organisation as required. The organisation can adapt the characteristics according to their own needs.

\begin{tabular}{|c|l|c|c|c|c|c|c|}
\hline \multirow{2}{*}{ Model Characteristic } & \multicolumn{6}{c|}{ Processes } & \multirow{2}{*}{$\begin{array}{c}\text { Characteristic } \\
\text { Total }\end{array}$} \\
\cline { 3 - 7 } & A & B & C & D & E & 60\% \\
\hline 1 & Shared Values & 1 & 0 & 0 & 1 & 1 & $\mathbf{6 0 \%}$ \\
\hline 2 & Style of Leadership & 0 & 1 & 1 & 1 & 0 & $\mathbf{6 0 \%}$ \\
\hline 3 & Structure & 1 & 1 & 0 & 1 & 1 & $\mathbf{8 0 \%}$ \\
\hline 4 & Skills & 0 & 1 & 0 & 1 & 0 & $\mathbf{4 0 \%}$ \\
\hline 5 & Systems & 0 & 1 & 0 & 1 & 1 & $\mathbf{6 0 \%}$ \\
\hline 6 & Staff & 1 & 1 & 1 & 1 & 1 & $\mathbf{1 0 0 \%}$ \\
\hline 7 & Strategy & 1 & 0 & 0 & 0 & 0 & $\mathbf{2 0 \%}$ \\
\hline 8 & Synergistic Teams & 1 & 1 & 1 & 1 & 0 & $\mathbf{8 0 \%}$ \\
\hline 9 & $\begin{array}{l}\text { Supporting } \\
\text { Infrastructure }\end{array}$ & 1 & 0 & 0 & 1 & 1 & \\
\hline \multicolumn{2}{|c|}{ Comparison Total } & $\mathbf{6 6 . 7}$ & $\mathbf{7 7 . 8}$ & $\mathbf{3 3 . 3}$ & $\mathbf{7 7 . 8}$ & $\mathbf{5 5 . 6}$ & \\
\hline
\end{tabular}

Table 1. Evaluation Matrix Example 


\subsection{Graphical Representation}

From the evaluation matrix two Radar plots can be produced. The process evaluation plot graphically represents how well the organisation performs when measured against the characteristics of the model. The process comparison plot compares the different processes in the organisation. Examples of the plots based on the completed evaluation matrix data are depicted in Figure 2 and Figure 3.

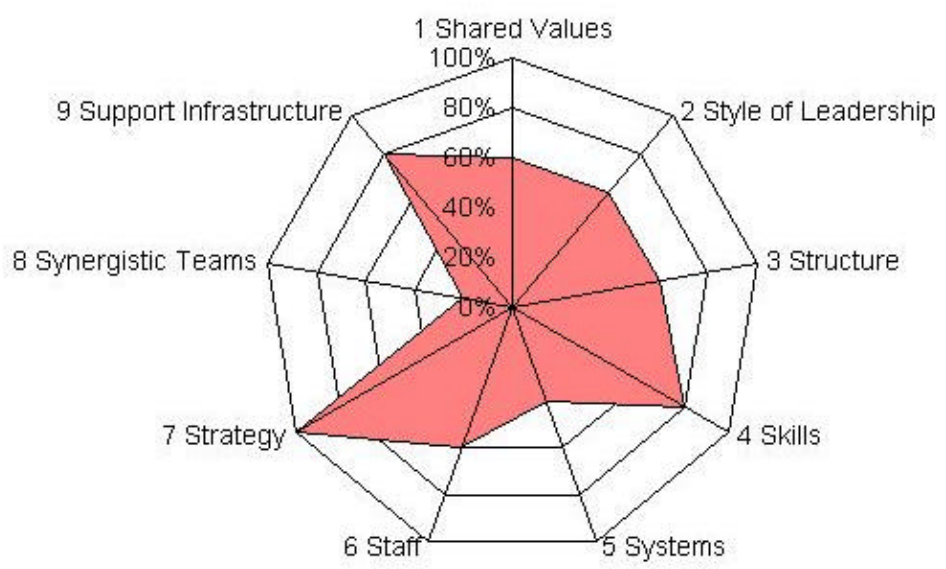

Figure 2. Process Evaluation Example

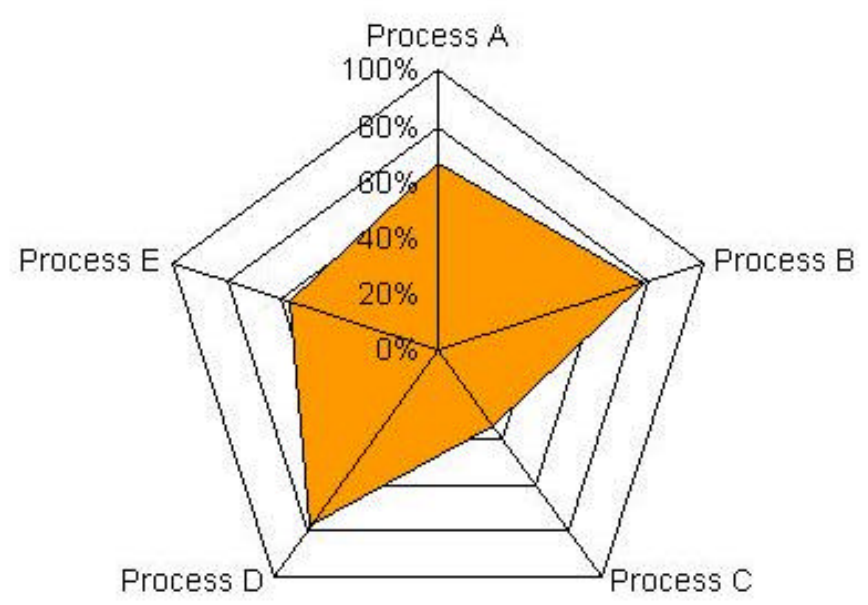

Figure 3. Process Comparison Example 


\subsection{Interpretation of Results}

From the scoring data and the plots, factors that limit and contribute to the processes can easily be identified. Comparison of the different processes indicates in which processes specific shortcomings exist. High scoring processes can be used as role models. This would improve the skills of individuals and, through them, the organisation as a whole.

\section{CASE STUDY}

\subsection{Introduction}

A case study was performed to evaluate the proposed model. This was done by assessing the main planning activities of an information technology (IT) division of an international organisation.

A short background on the general planning process is discussed after which the evaluation criteria that was used to assess the organisation is defined. This is followed by a summary of the background of the organisational as well as the planning processes that were evaluated. The case study concludes with the assessment results as well as a short discussion.

\section{The Planning Process}

Planning is defined as the process of setting goals and defining the actions needed to achieve those goals [13]. In order to do effective planning, it is necessary to fully understand the current situation in the organisation and know exactly what results the organisation wants to achieve.

In any organisation, there are two primary types of planning, i.e. strategic and operational planning.

\subsubsection{Strategic Planning}

Lewis [13] defines strategic planning as the process by which organisations make decisions and take actions to enhance their long-term performance. There are basically three levels at which strategic planning occurs, namely at corporate, business and functional level.

\subsubsection{Operational Planning}

Operational planning is the process of determining the day-to-day activities necessary to achieve the long-term goals of the organisation. Operational plans are often interrelated and aspects of all could be found in any organisation.

Due to the ever-changing environment in which organisations must operate, it is expected of managers to adapt their planning to accommodate these changes.

These operational plans can be categorised as standing or single-use plans. 


\section{Standing Plans}

Standing plans deal with issues and problems that recur frequently in the organisation. These plans ensure that situations are dealt with in a prescribed way and provide guidance to personnel in addressing issues. Examples of these plans are policies, procedures and rules.

\section{Single-use Plans}

Single-use plans address specific situations that would not typically recur. Some examples are programs, projects and budgets.

\subsubsection{Planning as a Learning Process}

The above mentioned traditional planning process of setting goals, defining actions, compiling plans, controlling actions and measuring outcomes is a mechanistic type of process that is partially in conflict with the requirements of a "learning whilst planning" approach. In this approach, planning actions, activities, policies and procedures are continuously questioned and analysed in order to improve not only the planning process but also the outcomes.

\subsection{Evaluation Criteria}

The evaluation criteria are a set of questions that were derived from the model characteristics, focussing on the planning processes involved within organisations. The different model characteristics are weighted in terms of relative importance and the questions are scored. Scoring is done by means of discussion and consensus as the assessment tool is for internal use to indicate possible areas for improvement. The evaluation criteria for each model characteristic are given in the following subsections.

\subsubsection{Shared Values}

Questions in this section are directed towards determining whether concepts such as Total Quality Management is used during the planning process and whether everyone in the organisation prepares and plans for excellence in all organisational activities and endeavours. In addition to this, the questions determine whether the primary focus of the planners is not on the finished product or result of the plan, but on the process of aligning the shared mental model with current reality, in order that the plans remain flexible and continuously improve to adapt to a changing environment.

- Does the organisation make use of concepts like TQM whilst planning?

- Are plans continuously reviewed?

- Do the members of the organisation behave in a way that is congruent with the espoused values of the organisation during planning activities? 


\subsubsection{Style of Leadership}

Questions in this section are directed towards determining whether the employees are encouraged to participate in the planning activities of the organisation and whether the leadership style is participative and of a facilitating nature.

- Are employees allowed to do their own planning?

- Are employees empowered to make their own decisions with regards to the planning process?

- Is guidance (not orders) given to staff during the planning process?

- Are employees actively encouraged to form part of the strategic planning process?

- Does management encourage employees to share ideas amongst one another?

\subsubsection{Structure}

Questions in this section are directed towards determining whether the structure of the organisation facilitates efficient and effective information flow to assist the planning activities. The evaluation criteria measures the availability of essential information required for proper planning.

- Does the organisation have dynamic networks?

- Is information flow through the organisation channelled in vertical flows?

- Are decisions integrated at all managerial levels?

- Do you have access to planning information outside your own immediate environment to use during planning?

- Does the organisation rotate responsibilities?

\subsubsection{Skills}

Questions in this section are directed towards determining whether there are sufficient opportunities for employees to acquiring the essential skills necessary for proper planning and whether the planning processes involve adaptive as well as generative learning.

- Are the participants in the planning process creative thinkers?

- Do the participants in the planning process make use of mental models?

- Are participants encouraged to use team learning as part of the planning process?

- Is systems' thinking applied to the planning process?

- Are the people in your planning process given the opportunity to acquire and enhance their skills through training and experimentation?

- Is the purpose of the plan, the planning process and the plan itself continually questioned?

\subsubsection{Systems}

Questions in this section are directed towards determining whether the organisation utilises balanced measures in evaluating the planning activities. 
- Does your organisation make use of balanced measurements?

- Are the measured results fed back to the planners of your organisation?

- Is the feedback used during planning processes?

\subsubsection{Staff}

Questions in this section are directed towards determining the individual commitment to learning about the planning process as well as creating an environment which is conducive to lifelong learning.

- Are mistakes tolerated during the planning process?

- Is training given to employees with regards to the planning processes?

- Are there improvement programs for individuals at all levels of the organisation in planning processes?

- Are people encouraged to attend courses or training programs?

- Are people given the opportunity to attend courses or training programs?

\subsubsection{Strategy}

Questions in this section are directed towards determining whether there is a personification of a shared vision, obtained from a collective mental model, in order to allow freedom of lateral thinking in the planning process. This is in contrast to a plan that is based on a fixed set of instructions. It also determines whether the planning strategy is comprehensive enough to avoid the need for crisis management.

- Is the organisation's strategic plan a vision created from a collective mental model?

- Is there enough time for planning?

- Is crisis management the exception rather than the rule?

- Is there a constant sharing of ideas about the future?

\subsubsection{Synergistic Teams}

Questions in this section are directed towards determining whether there is open dialogue during planning and decision making, whether team learning is encouraged, and whether individual expertise is used to enhance the team's capabilities.

- Are all members of the division asked for their input in the strategic planning process?

- Are members of other divisions asked for their input in the strategic planning process?

- Is the dialog open during planning sessions?

- Is all information available to all members of the planning session?

- Are members of other divisions asked for their input with regards to the planning done at operational level?

- Do members share their vision during planning sessions?

- Do all members "buy into" the ideas generated during planning sessions?

- Is there open and honest communication at all levels? 


\subsubsection{Supporting Infrastructure and Technology}

Questions in this section are directed towards determining whether an infrastructure that supports knowledge sharing is used.

- Is use of the Internet for organisational related research used and encouraged?

- Does the organisation have a central knowledge base?

- Does the organisation encourage the use of planning tools?

- Is the central knowledge base accessible to everyone within the organisation?

- Is use of the intranet for organisational related research used and encouraged?

- Does the office infrastructure encourage knowledge sharing?

- Is the office infrastructure used to effectively share knowledge?

\subsection{Organisational Background}

The organisation that was investigated in this case study is an international consultancy providing multi-disciplinary, professional services in engineering, infrastructure-related development and management. With its in-depth knowledge of a wide range of markets and industries gained over half a century, the organisation is capable of providing broad-based expertise and resources in both developed and developing countries. While maintaining a leading-edge approach focused on innovation and operational excellence, the organisation is continuing to extend its vast fields of expertise to include a diversified spectrum of services. Owing to the all-encompassing scope of work undertaken by the organisation, it has established a number of specialist divisions and associated companies, both in South Africa and internationally.

The organisation has been in existence since the early fifties and during the intervening years has grown to become one of the largest multi-disciplinary engineering consultants based in sub-Saharan Africa. The organisation, with a staff complement of over 1000 employees, is continuing to extend its vast fields of expertise to include a diversified spectrum of services.

The company makes use of a matrix structure comprising different divisions which are also represented in branch offices where the specific service is required. During this study only one of the divisions were investigated. This division has a staff complement of 134 people, comprising both technical and support staff. The division's turnover has constantly increased over the last couple of years and is estimated to be in excess of R 45 million for the 2001/2002 financial year. The division is further broken down into specialised business units.

\subsection{Planning Processes Addressed}

During interviews and subsequent work group discussions, five major planning processes were identified for evaluation by the authors. These planning processes are briefly discussed in the following two sections.

It must be emphasised that the five planning processes are not the only planning processes that occur in the specific organisation. These number of selected processes are however sufficient enough to demonstrate the value of the model and should indicate the current level of learning in the most common planning processes. 


\subsubsection{Strategic Planning Processes}

\section{Divisional Board Meeting (Planning Process A)}

These meetings take place on a bi-annual basis and are attended by all the directors on the Division under consideration as well as the CFO, the organisation's Corporate Services Director and the CEO of the Organisation. During the board meetings, future divisional direction, strategic positioning, as well as new strategies, are discussed. During this meeting, annual business plans for each business unit are also evaluated and improved.

\section{Divisional Executive Committee Meeting (Planning Process B)}

This meeting takes place on a bi-weekly basis and basically consists of two directors plus the Managing Director and the accounting manager of the division. The other directors are involved on a rotational basis. Occasionally, and as the need arises, other directors from the division are also involved. The objective of these meetings is to focus on the planning and implementation of the set strategy and breakdown into action steps. In addition to this, operational and day-to-day aspects are discussed. This meeting is also used to address implementation problems and other unresolved issues.

\subsubsection{Operational Planning Processes}

\section{Project Procurement Planning and Tender Reviews (Planning Process C)}

There are several tender meetings in the company. The following planning meetings are held on a weekly basis:

- National tender meeting to discuss opportunities/tenders/request for proposal nationally - This meeting is attended by representatives from all the divisions.

- International tender meeting to discuss opportunities/tenders/request for proposal internationally - This meeting is attended by representatives from all the divisions.

- Ad hoc meetings as and when required.

- Divisional tender meetings attended by directors from the business unit leaders within the division.

- Tender meetings within each business units attended by the directors and/or staff members.

\section{Project Execution Planning (Planning Process D)}

These meetings are scheduled to plan for project execution and is on an as and when basis. The agenda is also structured around deliverables in the projects and includes aspects across the entire project i.e. technical, progress, quality, financial etc. Team leaders from all levels are normally involved in these meetings. Depending on the duration of the project, there can be several meetings over the life span of the project and the number of meetings per project thus varies very much. 


\section{Post Project Implementation Planning and After Care (Planning Process E)}

As in the case of the project execution planning, these are ad hoc meetings as well as structured meetings to review progress and other implementation of after care actions. Due to the nature of the tasks/deliverables, directors seldom attend these planning sessions, except if crucial decisions have to be taken. The agenda includes all aspects relating to the after care and resolves around optimisation of the activities.

\subsection{Assessment}

The organisation was assessed according to the developed model and the different evaluation criteria were scored. The detailed scoring method is beyond the scope of this publication. A scoring summary of this matrix is depicted in Table 2 and graphically presented in Figure 4 and Figure 5.

\begin{tabular}{|c|l|c|c|c|c|c|c|}
\hline \multirow{2}{*}{$\begin{array}{c}\text { Learning whilst Planning } \\
\text { Characteristic }\end{array}$} & \multicolumn{5}{|c|}{ Planning Processes } & \multirow{2}{*}{$\begin{array}{c}\text { Characteristic } \\
\text { Total [\%] }\end{array}$} \\
\cline { 2 - 7 } & A & B & C & D & E & $\mathbf{9 1}$ \\
\hline 2 & Shared Values & 100 & 100 & 85 & 93 & 78 & $\mathbf{8 5}$ \\
\hline 3 & Style of Leadership & 90 & 90 & 90 & 75 & 79 & $\mathbf{8 0}$ \\
\hline 4 & Structure & 86 & 86 & 79 & 79 & 69 & $\mathbf{7 7}$ \\
\hline 5 & Skills & 98 & 98 & 82 & 63 & 46 & $\mathbf{7 3}$ \\
\hline 6 & Staff & 93 & 93 & 50 & 73 & 58 & $\mathbf{6 8}$ \\
\hline 7 & Strategy & 65 & 65 & 55 & 80 & 76 & $\mathbf{7 1}$ \\
\hline 8 & Synergistic Teams & 100 & 100 & 55 & 62 & 37 & $\mathbf{7 3}$ \\
\hline 9 & $\begin{array}{l}\text { Supporting } \\
\text { Infrastructure }\end{array}$ & 78 & 78 & 70 & 66 & 63 & $\mathbf{7 1}$ \\
\hline Comparison Total [\%] & $\mathbf{8 8}$ & $\mathbf{8 8}$ & $\mathbf{6 9}$ & $\mathbf{7 3}$ & $\mathbf{6 4}$ & \\
\hline
\end{tabular}

Table 2. Evaluation Matrix 


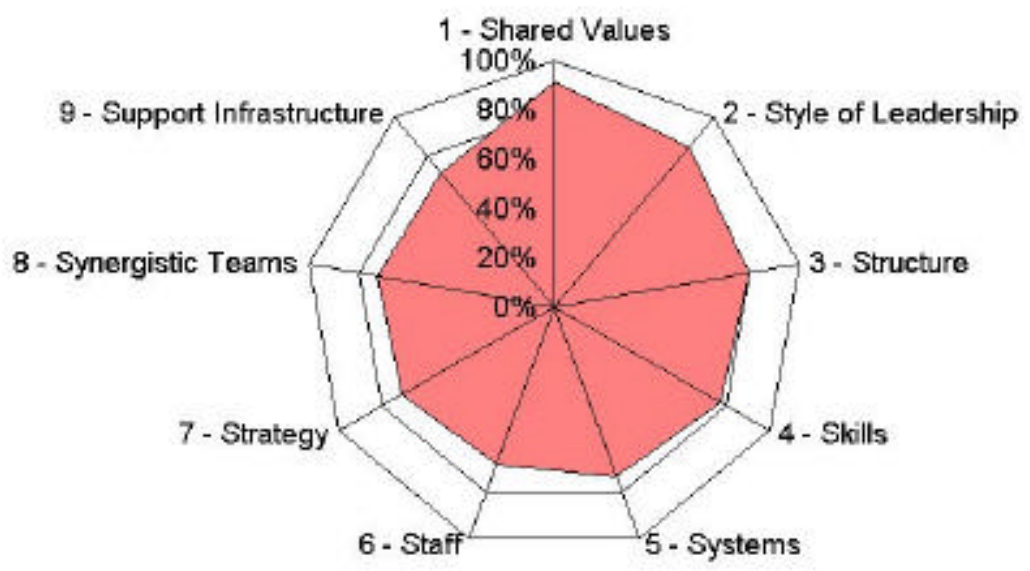

Figure 4. Learning whilst Planning Evaluation

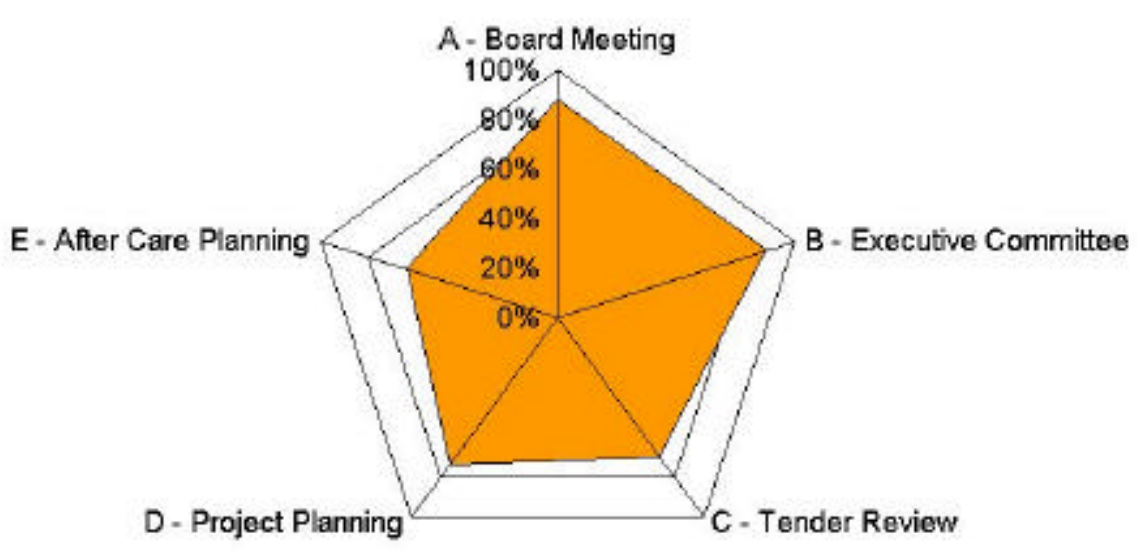

Figure 5. Planning Process Comparison

\subsection{Discussion}

The overall high scores indicated by the evaluation is proof positive that the organisation has adapted well with the changing environments of the last 5 decades. The organisation indeed has a culture of learning, as indicated by the high scores in the shared values, leadership style and structure criteria. The evaluation also indicates that the organisation is somewhat lacking in planning support infrastructures, and that staff still need to grow some of the skills needed to fully the embrace the advantages of learning whilst planning. 


\section{CONCLUSION}

Successful organisations in the current volatile global economy display many characteristics that are in line with the concepts and principles of learning organisations. In many instances, these organisations have developed their own activities and structures that allow them to be competitive and successful. The 9-S framework and accompanying assessment model is based on the characteristics of learning organisations and provides organisations with a generic way of measuring their compliance with necessary learning characteristics. The assessment model has been applied to the planning activities of an organisation in the case study, and from the results it can clearly be seen where the organisation can improve its planning activities to be more in line with learning characteristics. The framework encompasses all activities of organisations and the assessment model can easily be expanded to measure most organisational activities. By using the framework and the model, organisations can easily measure internal improvement on a time-history basis.

\section{REFERENCES}

[1] Ayas, K., 1996, "Design for Learning and Innovation, Long Range Planning", Vol. 29(6):898-901.

[2] Argyris, C., 1991, “Teaching Smart People How to Learn”, Harvard Business Review.

[3] Cathon, D.E., 2000, "The Learning Organization: Adapted from The Fifth Discipline by Peter Senge", Aspen Publishers.

[4] Charan, R. 1991, "How Networks Reshape Organizations - for results", Harvard Business Review, September-October.

[5] De Geus, A.P. 1998, "Planning as Learning, Harvard Business Review", Mar-Apr 1998.

[6] Eppel, R.C., Conklin, E.J., "Blending Cultural Transformation and Groupware to Create a Learning Organization", GDSS Working Papers.

[7] Garvin, D.A., 2000, "Learning to Lead", CIO Magazine.

[8] Garvin, D.A. 1993, "Building a Learning Organization", Harvard Business Review, JulAug 1993:78-91.

[9] Guthrie, D., 1996, "Transforming an Existing Organization into a Learning Organization", Group Decision Support Systems, Inc.

[10] Hitt, William D., 1995, "The Learning Organisation: Some Reflections on Organisational Renewal", Leadership \& Organisation Development Journal, Vol. 16 No 8, 1995:17-25, MCB University Press Limited.

[11] Kaplan, S., Norton, D.P., 1992, “The Balanced Scorecard - Measures that Drive Performance", Harvard Business Review.

[12] Kaplan, S., Norton, D.P., 1993, "Putting the Balanced Scorecard to Work", Harvard Business Review.

[13] Lewis, P.S., et al, 2001, "Management Challenges in the 21st Century, 3rd Edition", South-Western College Publishing.

[14] Nevis, E.C., DiBella, A.J., Gould, J.M., 1995, "Understanding Organizations as Learning Systems", Sloan Business Review, Winter 1995.

[15] Oakland, J., 2000, "Total Quality Management, Text with Cases, 2nd Edition", Butterworth-Heinemann.

[16] Senge, P.M., 1990, "The Fifth Discipline, The Art and Practice of The Learning Organization", Random House Business Books. 
[17] Senge, P.M., Roberts, C., Ross, R.B., Smith, B.J., Kleiner, A., 1994, "The Fifth Discipline Fieldbook, Strategies and Tools for Building a Learning Organization", Nicholas Brealey Publishing Ltd.

[18] Shell, 1997, "Over 25 Years of Learning to Learn", The Antidote, CSBS, Issue 10:3540, 1997.

[19] Sugarman, B., "Learning, Working, Managing, Sharing: The new Paradigm of the Learning Organization". 